\title{
A Trindade e a GLória do ESTAdo Moderno:
}

uma análise a partir dos acontecimentos de junho de 2013

\author{
THE TRINITY AND GLORY OF THE MODERN STATE: \\ analysis through the prism of June 2013 events
}

\section{Daniel Santos Souza*}

\begin{abstract}
RESUMO ${ }^{1}$
Este artigo realiza uma análise político-teológica do estado a partir dos acontecimentos de junho de 2013. Esses eventos foram decisivos para a compreensão da política brasileira, pois colocaram em questão os modos de vida esperados em uma dinâmica de cidade e, também, os modos de organização da política em sua democracia liberal. O ponto decisivo desse texto é apresentar a relação entre dois polos do estado (soberania e biopolítica) como uma determinada teologia trinitária, algo evidenciado pelo filósofo Giorgio Agamben. A hipótese é que junho desvela essa atuação da máquina governamental. Com essa perspectiva, metodologicamente, esse artigo analisa, desde as provocações agambeanas, algumas grafias - como pichações, cartazes e faixas feitas durante esse período. Como estrutura, esse artigo está dividido em algumas partes: i) uma introdução que retoma a técnica como uma problemática de junho de 2013; ii) a investigação das relações entre trindade e o estado moderno; iii) a apresentação da inoperosidade no centro da máquina governamental do estado; e iv) a relação entre as tentativas de encobrimento do vazio anárquico do estado, por meio dos dispositivos aclamatórios, e os rastros de junho potentes em sua capacidade inoperosa.
\end{abstract}

Palavras-chave: Giorgio Agamben. Estado moderno. Teologia trinitária. Junho de 2013. Dispositivos aclamatórios. Teologia política.

\begin{abstract}
This article aims to bring a political-theological analysis of the state since the events of June 2013. These events were decisive for the understanding of Brazilian politics, as they question the ways of life expected in a city dynamic and, also, the ways of organizing politics in its liberal democracy. An important point of this text is to present the relationship between two poles of the state (sovereignty and biopolitics) as a determined Trinitarian theology, something already evidenced by the philosopher Giorgio Agamben. The hypothesis is that June unveils the performance of the government machine. With this perspective, this article methodologically analyzes some spellings, such as graffiti, posters and banners, made since the agambean provocations. This article is structured into a few parts: i) an introduction taking up the technique as a problem in June 2013; ii) the analysis of the relations between trinity and the modern state; iii) the presentation of inoperability at the center of the state's government
\end{abstract}

\footnotetext{
* Doutor (2019) e Mestre em Ciências da Religião (2013). Licenciado em Filosofia (2011) e Bacharel em Teologia (2010) pela Universidade Metodista de São Paulo (UMESP). Participa do Grupo de Pesquisa: Perspectivas Críticas da Filosofia Moderna e Contemporânea (UFABC/CNPq). Atualmente, é Pesquisador Doutor Colaborador na Universidade Federal do ABC (UFABC), em uma investigação de pós-doutorado sobre as formas-de-vida nas ocupações de moradia no centro da cidade de São Paulo. Número ORCID: ooooooo2-4144-8755. E-mail: dan.vca@gmail.com.

${ }^{1}$ Esse texto é uma versão adaptada de um dos tópicos da minha tese de doutorado: A revolta da ineficiência: os acontecimentos de junho de 2013 no Brasil e suas destituições político-teológicas (2019), defendida no Programa de Pós-graduação em Ciências da Religião da UMESP.
} 
machine; and iv) the relationship between the attempts to cover the state's anarchic void, using some acclaiming devices, and the tracks of June which are potent in their inoperative capacity. Keywords: Giorgio Agamben. Modern State. Trinitarian Theology. June 2013. Acclaiming devices.

\section{INTRODUÇÃO: A TÉCNICA ESCANCARADA EM JUNHO DE 2013}

Deixar o rei nu antes que ele desnude a nós. (BOLTON, 2017, p. 6)

Em 11 de junho de 2017, a Revista Piauí publica o artigo de Fernando Haddad: Vivi na pele o que aprendi nos livros - um encontro com o patrimonialismo brasileiro (HADDAD, 2017). No início desse texto, aparece uma tensão entre Dilma (PT) e Haddad (PT) sobre o reajuste da tarifa de ônibus no município de São Paulo. A causa: como controlar a inflação. A manutenção do valor da tarifa - para a equipe econômica do Planalto - era fundamental, especialmente depois de um congelamento dos reajustes em dois anos. A proposta de Haddad era a municipalização do Cide - Contribuição de Intervenção no Domínio Econômico, que incide sobre a comercialização da gasolina, do diesel e seus derivados, um tributo da União. Para ele, o subsídio do transporte público sairia daí. A ideia foi recusada. O antigo prefeito - depois da reunião - afirmou que alguma coisa estava errada: “[...] não se pensa em controlar a inflação de um país continental pelo represamento de uma tarifa municipal sem atravessar estágios intermediários e sucessivos de uma compreensão equivocada.” (HADDAD, 2017, p. 30). Segundo Haddad, o governo Dilma desejava uma estabilidade macroeconômica via um intervencionismo microeconômico. ${ }^{2}$

Aqui está um ponto importante no debate sobre os acontecimentos de junho: olhares econômicos no horizonte da técnica. Tanto Dilma como Haddad circularam nesse universo. Por exemplo, em uma reunião entre o prefeito e o MPL-SP (Movimento Passe Livre):

Haddad pede a definição de uma fonte orçamentária do subsídio que reivindicam e questiona o movimento sobre sua suposta indisposição em negociar. O MPL diz que não cabe ao movimento encontrar soluções técnicas para uma demanda social e afirma que sempre esteve aberto a discutir a revogação do aumento (JUDENSNAIDER et al., 2013, p. 159).

\footnotetext{
${ }_{2}^{2}$ Para uma consistente análise sobre a economia brasileira nesse período (e também de outros momentos do lulismo), conferir o livro de Laura Carvalho (2018). Para esse momento, verifique o capítulo 2: A agenda Fiesp: um passo ao lado (CARVALHO, 2018, p. 55-96).
} 
Quem encontrará a saída para a gestão do transporte e para a mobilidade numa cidade como São Paulo? O diálogo na reunião entre o prefeito e o movimento revelou o que Sandro Chignola (2017) chamará de tecnicização da decisão política. Ele explica: por ser técnica, a decisão é “[...] cada vez mais subtraída dos procedimentos de formação e de controle das instituições democráticas.” (CHIGNOLA, 2017, p. 34). Com os diálogos desde Foucault, podemos indicar a técnica como um saber-poder, um discurso que pode ordenar e construir regimes de verdade (FOUCAULT, 2017). Ou desde Agamben, poderíamos apontar que o debate feito em junho, com ênfase na tarifa, guiou-se como um dispositivo da técnica. Uma política - com todas as intenções biopolíticas de garantia da vida (e sobrevida) - ditada pelas "[...] supremas razões da eficiência econômica ou do mercado, orientada por problemas de segurança, modulada sobre as exigências do capital.” (CHIGNOLA, 2017, p. 34). As decisões sobre junho não transformaram a política em técnica, elas a escancararam. Como isso acontece?

Quando a decisão - tomada em conjunto por Fernando Haddad (PT) e Geraldo Alckmin (PSDB) - de redução da tarifa é anunciada, o argumento novamente é colocado no espaço da técnica. Alckmin (2013), por exemplo, argumentou que o cancelamento do reajuste do metrô e do trem "[...] é um sacrifício grande, vamos ter que cortar investimentos, porque as empresas não têm como arcar com essa diferença. Vamos arcar com esses custos fazendo ajustes na área de investimentos.” (ALCKMIN, 2013). Haddad (2013) seguiu a mesma linha da dificuldade em se manter o equilíbrio das contas: “Conforme o governador disse, não há como fazê-lo sem dispensas no investimento. O investimento acaba sendo comprometido. Então, esse debate vai ser feito com a sociedade. As implicações dessa medida [...]” (HADDAD, 2013). Essa tecnicização da decisão com um sacrifício guiado pela austeridade dos governos, combinados com a manutenção dos lucros das empresas, colocou a reivindicação das ruas diante de uma encruzilhada. Aceitase as regras do jogo e apresenta-se um plano popular de subsídios e organização da gestão do transporte público? Limitar-se a esse caminho - escreve o Comitê invisível - "[...] é ter a certeza que a luta será perdida, uma vez que admite implicitamente uma ideia de vida que não nos convém.” (COMITÊ INVISÍVEL, 2016, p. 61). Esperar de junho uma eficiência econômica - das ruas ou dos gabinetes - é não entender o centro da questão que foi colocada nesses atos: uma outra ideia de vida, outra possibilidade de viver e habitar a cidade.

Os acontecimentos de junho deixam o rei nu. Essa articulação entre gestão eficientede-planilhas-e-reuniões (biopolítica) e a soberania estruturada na exceção e busca de 
segurança/ordem, basta recordarmos os discursos de representantes políticos naquele período, 3 só é possível devido a uma dimensão teológica. Aqui está um ponto decisivo desse artigo. Assumo essa suspeita a partir das reflexões de Giorgio Agamben. Edgardo Castro (2013), ao comentar a obra desse filósofo, indica que o autor de $O$ reino e a glória (AGAMBEN, [2007]2011) compreende que o estado4 moderno possui três grandes paradigmas que influenciam o desenvolvimento e a ordem política do ocidente: o jurídico, o teológico e o biopolítico (CASTRO, 2013). O estado se organiza a partir de sua lógica soberana e sagrada (teológico), com referência em marcos legais e como um estado de exceção (jurídico) e com a capacidade de regular corpos, vidas e populações (biopolítica). Mas em seu coração temos um trono vazio. O centro da máquina governamental está vazio. Como escreve Agamben (2011): “[...] o trono vazio, o símbolo da glória, é o que deve ser profanado para dar lugar, para além dela, a algo que, por ora, podemos apenas evocar com o nome zoé aiõnios, vida eterna" (AGAMBEN, 2011, p. 11). Junho - visto em suas grafias e opiniões polifônicas - escancara o vazio desse trono, o vazio do estado moderno. E nesse desvelar, no centro da política, encontramos a “inoperosidade” (AGAMBEN, 2011, p. 11), algo que aprofundarei com mais detalhes no tópico a seguir.

\section{A MÁQUina goVERNAMENTAL COMO UMA BINDADE: E O VAZIO?}

Parece estranho para as análises mais modernas, elaboradas desde a dicotomia entre religioso e secular, público e privado, uma ideia de um estado teológico. A base para essa leitura está nos imaginários de um Deus soberano que governa o mundo e a vida social (AGAMBEN, 2011, p. 13). Assim, a imagem de um único Deus e a sua transcendência e poder, junto com a capacidade de governo da vida humana, fundamentam o estado moderno em sua soberania e em sua organização e modo de atuação. O estado assume o seu lugar sagrado (atrelado ao capital e desejo de privatização do público) e regula as vidas, os corpos e os modos de viver e existir nos espaços da cidade. As imagens de um Deus todo-poderoso,

\footnotetext{
${ }_{3}^{3}$ Sobre isso, vale resgatar o pronunciamento de Dilma Rousseff em 21 de junho de 2013. Nele, a presidenta faz um elogio a uma democracia ordeira. Ela é enfática: "asseguro a vocês: vamos manter a ordem". O Governo e sociedade - afirma Dilma - "não podem aceitar que uma minoria violenta e autoritária destrua o patrimônio público e privado, ataque templos, incendeie carros, apedreje ônibus e tente levar o caos aos nossos principais centros urbanos" (ROUSSEFF, 2013).

4 A grafia da palavra estado parece incomum. A norma da escrita nos orienta para uma grafia em letra maiúscula: Estado. Há uma decisão política na construção da própria língua, uma marcação que evidencia o lugar dessa entidade em nossa formação política. A escolha que faço nesse texto segue a tentativa de desativar a língua por meio da própria língua. Desativar o lugar sagrado e separado do estado por meio de uma mudança na escrita. É o desejo de se falar do estado para além da sua retirada e sua elevação do espaço comum. De algum modo, essa opção é também um exercício de profanação, uma aproximação com o pensamento de Giorgio Agamben.
} 
soberano e patriarcal legitimam e são a referência do estado. Mas o contrário também é verdadeiro. O modo de atuação do estado legitima e necessita do Deus Pai todo-poderoso. Há uma retroalimentação dos dois polos desde o que são e como atuam e exercem o governo (ser e práxis).

Nesse exercício a que me proponho, é preciso reconhecer o trabalho de Agamben em estabelecer uma genealogia teológica da economia e do governo. Algo presente no livro O reino e a glória (AGAMBEN, 2011). Nesse estudo, Agamben (2011) afirma que se derivam da teologia cristã - de modo amplo - dois paradigmas políticos:

[...] antinômicos, porém funcionalmente conexos: a teologia política, que fundamenta no único Deus a transcendência do poder soberano, e a teologia econômica, que substitui aquela pela ideia de uma oikonomia, concebida como uma ordem imanente - doméstica e não política em sentido estrito - tanto da vida divina quanto da vida humana (AGAMBEN, 2011, p. 13).

Giorgio Agamben encontra uma relação fundamental entre a doutrina trinitária e a política. As relações internas da trindade (trindade política) - focadas na unidade e diversidade trinitária - e as suas relações externas (trindade econômica), compreendidas como a ação salvadora do Deus trino no mundo - implicam em imaginários e modelos políticos. Como afirma o próprio Agamben (2011): “[...] do primeiro paradigma derivam a filosofia política e a teoria moderna de soberania; do segundo, a biopolítica moderna até o atual triunfo da economia e do governo sobre qualquer outro aspecto da vida social” (AGAMBEN, 2011, p. 13). Por meio da teologia, Agamben encontra a conexão entre dois polos da política moderna. O seu estudo, segundo Rodrigo Bolton (2017), tem quatro pontos significativos: (i) evidenciar que a doutrina cristã de providência foi constituída como uma estratégia para articular a dicotomia entre ser e práxis, herdada de Aristóteles; (ii) mostrar que a máquina providencial da trindade - como antessala da máquina governamental dos modernos - torna possível a combinação entre reino (soberania) e governo; (iii) dessubstancializar o poder - numa linha foucaultiana - e mostrar, como já indiquei, que o seu centro é o trono vazio, escondido pelas dinâmicas de glorificação; e (iv) indicar que a oikonomia da modernidade configura as democracias liberais como verdadeiras "democracias gloriosas" (BOLTON, 2017, p. 20), emancipando o dispositivo espetacular para toda a vida social.

O debate feito por Agamben coloca em tensão dois autores importantes, C. Schmitt e Erik Peterson, que dialogaram em textos de 1935 a 1970. Os dois procuram “[...] fundamentar na fé cristã uma política” (AGAMBEN, 2011, p. 28). Essa leitura é organizada 
com o horizonte escatológico do reino de Deus, com a esperada volta de Cristo. No entanto, aqui há uma das principais diferenças entre eles:

[...] os autores divergem entre si sobre qual o motivo que atrasa, de fato, a parusia de Cristo, o katechon. Para Schmitt, o que impede o retorno de Cristo é a existência de um império cristão: a realização política da fé cristã, na forma de império cristão, é o katechon que retrasa o fim dos tempos. Peterson, diferentemente, entende que o katechon que impede a segunda volta de Cristo é a falta de conversão dos judeus. Para Peterson, a conversão dos judeus será o passo final antes da parusia. Esse retraso (katechon) justifica a existência da Igreja, a qual, na volta de Cristo, desaparecerá por não ser mais necessária (RUIZ, 2014, p. 193).

Daí decorrem duas perspectivas. De um lado, para Schmitt, temos que a teologia política fundamenta a política em seu sentido mundano; do outro, Peterson aponta o problema de uma teologia política guiada por um monoteísmo e resgata o agir político cristão centrado na liturgia como práxis pública, em que a teologia cristã não se guia pela política, mas pela oikonomia, uma economia de salvação (AGAMBEN, 2011, p. 28-29). Junto a essa leitura, temos a seguinte tese de Peterson: “[...] o culto da Igreja celestial e, por isso, naturalmente também a liturgia da Igreja terrena, que se une à celestial, têm uma relação originária com o mundo político.” (PETERSON apud AGAMBEN, 2011, p. 162). Há um espelhamento entre o culto terreno e celestial - como em Agostinho e sua Cidade de Deus e Cidade dos homens. Segundo Castor Ruiz (2014), na liturgia, “[...] os anjos participam em primeira instância, mas a ekklesia também participa ativamente, politicamente, dessa relação cultual.” (RUIZ, 2014, p. 197). Os anjos são símbolos da burocracia 5 que garantem a relação entre a Igreja celeste e a Igreja terrena, numa dinâmica em que a política se realiza como liturgia política na cidade celeste; eles são “[...] os fiadores da relação originária entre a igreja e a esfera política, do caráter 'público’ e 'político-religioso' do culto que se celebra tanto na ekklèsia quanto na cidade celeste”

\footnotetext{
5 Vale lembrar que esta burocracia não é originalmente cristã. Trata-se de uma adaptação cristã dos monoteísmos pagãos da antiguidade Greco-romana. Uma estratégia bem-sucedida do cristianismo primitivo para se apropriar do conceito de daemons, filtrando/recriando sua atuação para que qualquer espírito que atuasse fora da lógica do monoteísmo cristão passasse a ser considerado como maligno e diabólico (FRASER, 2009, p. 136-137).
} 
(AGAMBEN, 2011, p. 164).6 Há, aqui, entre esses dois paradigmas (Schmitt e Peterson), na divindade, uma fratura entre ser e práxis. "O rei reina mas não governa”, provoca Peterson (apud SEREJO, 2018, p. 217). Assim, em sua teologia nasce a importância dos anjos administradores do mundo. No âmbito político, surge a urgência do governo centrado na "glória e na aclamação" (SEREJO, 2018, p. 217).

Esses dois paradigmas se sustentam numa articulação dentro de uma determinada teologia trinitária, nessa teologia feita como bindade. Explico. Boa parte dos diálogos sobre a trindade na teologia ocidental, na verdade, são guiados por uma “[...] ênfase particular em Cristo e no pensamento cristológico, uma forma de cristomonismo que tem sido utilizada para justificar e legitimar imposições imperiais por parte do ocidente" (DICKINSON, 2017, p. 6). A ênfase colocada está na relação entre Pai e Fïlho, com a finalidade de combater o arianismo.7 Esse binômio soberano tem a dificuldade de ser rompido, mesmo com a entrada do Espírito Santo como o terceiro termo. Agamben apresenta uma crítica a essa bindade. No fundo, a sua interpretação estaria mais próxima daquelas expoentes “[...] da teologia feminista, queer e outras teologias contextuais que articularam uma vasta crítica das formas opressoras heteronormativas e estritamente binárias de gênero e sexualidade" (DICKINSON, 2017, p. 7).8

Não é novidade, no campo da teologia, esse encobrimento do Espírito Santo e a construção da trindade como uma relação hegemônica entre Pai e Filho, a constituição de uma bindade. A intenção é política. Retomemos Niceia (325) e Calcedônia (451). No primeiro, temos a afirmação que “[...] nós acreditamos em um Deus... e em um Senhor Jesus Cristo, o Filho de Deus, o único nascido do Pai, que é a substância do Pai, Deus de Deus, luz de luz, verdadeiro Deus do verdadeiro Deus, nascido e não feito, consubstancial

\footnotetext{
${ }^{6}$ Para Giorgio Agamben, “[...] na teologia cristã, os anjos são, acima de tudo, os ministros do governo divino do mundo, que, ordenados em nove hierarquias ou ministérios, executam a cada instante, tanto no céu como na terra, os decretos da providência. No Ocidente cristão, a angiologia tem funcionado como paradigma da burocracia, e a nossa concepção das hierarquias ministeriais tem sido profundamente influenciada por este paradigma celeste" (AGAMBEN apud SEREJO, 2018, p. 217). Castor Ruiz (2014) também escreve sobre os anjos: "No caso que nos ocupa, Agamben mostra como a teologia sobre os anjos preocupou-se em diferenciar entre os anjos dedicados meramente ao culto e os anjos que atuam como ministros de Deus. Estes assumem tarefas e ministérios que ajudam no governo providencial do mundo, preservando Deus de uma intervenção direta nas coisas cotidianas do mundo e respeitando nos homens o seu livre arbítrio" (RUIZ, 2014, p. 199).

$7 \mathrm{O}$ arianismo se coloca como uma tendência teológica em relação à trindade. Ário, discípulo de Luciano de Antioquia, defendia, próximo do seu mestre, uma compreensão sobre a relação entre pai e filho baseada no adocionismo e subordinacionismo, negando a divindade do filho, sua eternidade e sua consubstancialidade com o pai (LEXICON, 2003, p. 49). As interpretações desse debate - central para o Concílio de Niceia - são bem construídas por Joerg Rieger, em seu livro Cristo e o Império (2009), especialmente o capítulo: "Resistir e reestruturar a coigualdade: a cristologia e os credos" (RIEGER, 2009, p. 40-76).

${ }^{8}$ Entre esses nomes, temos Marcella Althaus-Reid, que "[...] muitas vezes citou favoravelmente a obra de Agamben como uma tentativa filosófica central de deixar para trás os sistemas binários de pensamento que têm guiado a política ocidental desde o seu início" (DICKINSON, 2017, p. 7-8).
} 
(homoousios) com O Pai” (RIEGER, 2009, p. 53). Enquanto Ário afirmava uma relação hierárquica, Niceia afirmava uma igualdade entre Pai e Filho. Calcedônia, segundo J. Rieger (2009), dá um passo além, quando explica o termo homoousios não somente como o relacionamento entre "[...] a primeira e a segunda pessoas da trindade, mas também no relacionamento entre a humanidade de Jesus e a nossa humanidade" (RIEGER, 2009, p. 53). Qual interesse político-teológico nessa articulação e formulação nos séculos quarto e quinto? Nas antigas teologias, uma palavra importante é condescendência. Aqui, tem-se uma compreensão que Deus teve "[...] condescendência de se juntar aos seres humanos na pessoa de Cristo" (RIEGER, 2009, p. 55). Estamos no terreno do Império Romano. A coigualdade do imperador se desdobra dessas noções teológicas. O problema central da cristologia nesse período, segundo Peter Brown, é "[...] combinar um sentimento de companheirismo com o exercício absoluto do poder" (BROWN apud RIEGER, 2009, p. 55). Aqui temos o ponto central. O problema é manter o poder absoluto do Imperador autocrata divinizado junto à irmandade da carne humana entre o imperador e seus outros "[...] homens santos [...] porque o próprio Cristo havia se rendido, para se tornar um homem semelhante àqueles que ele governava." (RIEGER, 2009, p. 56). Finalmente, diz Rieger (2009), “[...] o tipo de 'rendição' no caso do imperador é realmente uma questão de condescendência e o fluir do poder de cima para baixo não é questionado" (RIEGER, 2009, p. 56).9 Aqui encontramos uma combinação importante que, desde a coigualdade e reconhecimento da condescendência, pode legitimar a dinâmica em que o estado se mostra absoluto e ao mesmo tempo próximo do mundo por meio da gestão da vida. Ou melhor: o modo de operação do estado em seu exercício de garantia da ordem, da paz e da segu rança (basta resgatarmos o Leviatã) junto à sua tarefa de governar populações, corpos e territórios assume o mesmo esquema da bindade.

O que me interessa aqui é encontrar um elemento anárquico, o vazio que pode ser destituinte dentro de Deus, dentro do estado-feito-deus. Esse vazio, entre a coigualdade pai-filho, é encoberto pela glória, que, como uma fumaça, deixa nebulosa a relação entre soberania e governamentalidade, entre o ser e a práxis de Deus, entre a trindade política e a trindade econômica. Mais especificamente, o problema é a relação entre reino e governo, articulada como um único mecanismo político-teológico. Assim, o “[...] governo glorifica o reino e o reino glorifica o governo [...]. E a glória nada mais é que o esplendor

\footnotetext{
9 Há outras interpretações da trindade que não foram levadas em consideração na leitura de Giorgio Agamben, por exemplo, a própria interpretação de J. Moltmann, que é lido pelo filósofo italiano em $O$ reino e a glória (2011), porém de maneira mais superficial, sem levar em consideração a noção de pericorese, tão importante nas leituras trinitárias de Moltmann.
} 
que emana desse vazio, o kabod inesgotável que revela e, ao mesmo tempo, vela a vacuidade central da máquina” (AGAMBEN, 2011, p. 231). É como se o estado operasse em uma teatralidade litúrgica para esconder a anarquia capturada de fora dele. Como, então, tocar o vazio do estado-deus? Como deixar o rei nu?

\section{A INOPEROSIDAdE E O HIATO DAS MÁQUINAS}

Agamben, em O Reino e a Glória (2011), faz uma genealogia do governo e da economia, realizando um estudo sobre a liturgia, o poder e a glória. Como ele mesmo pergunta: “[...] por que o poder precisa de glória? Se é essencialmente força e capacidade de ação e governo, por que assume a forma rígida, embaraçosa e 'gloriosa' das cerimônias, das aclamações, dos protocolos? Qual a relação entre economia e glória?” (AGAMBEN, 2011, p. 10). A glória deixa nebulosos os hiatos/vazios das maquinarias modernas, especialmente no estado. Para entendermos a lógica desses polos (uma certa bindade), tomemos alguns exemplos. As cidades fundamentam-se nessa cisão da vida em vida natural e vida politicamente qualificada; o humano se fundamenta na exclusão-inclusão do animal; a lei se sustenta na própria exceção da anomia; o governo acontece na exclusão e ao mesmo tempo na captura, via a glória, da “inoperosidade” (AGAMBEN, 2017, p. 297). Em uma leitura binária, a retomada arqueogenealógica ${ }^{10}$ de Agamben poderia proporcionar um acirramento das polaridades para se efetivar a destruição do esquema excludente-includente das cidades, do humano, da lei e do governo. Mas não é esse o caminho. Evidenciar o limiar dessas cisões, que constitui uma determinada arché, pode resultar em processos de desativação da máquina jurídico-política do ocidente.

Como escreve Agamben (2017), referindo-se a seu livro O aberto: o homem e o animal ([2002] 2013):

[...] a máquina antropológica do ocidente havia sido definida pela divisão e articulação, no interior do homem, entre o humano e o animal. No final do livro, o projeto de uma desativação da máquina que governa nossa concepção do homem exigia não tanto buscar novas articulações entre o animal e o humano quanto, acima de tudo, expor o vazio central, o hiato que separa - no homem - o homem e o animal (AGAMBEN apud AGAMBEN, 2017, p. 297).

Ocupar o hiato que separa a vida natural da vida politicamente qualificada, o humano do animal, a lei da anomia, a exclusão-inclusão da inoperosidade no governo, é o

${ }^{10}$ Sobre as discussões sobre o método agambeano, conferir, entre outros textos: GIACOIA JUNIOR (2018). 
desafio que nos coloca Giorgio Agamben. Como escreve mais diretamente: “[...] o problema ontológico-político fundamental hoje não é a obra, mas a inoperosidade, não é a complicada e incessante busca de nova operabilidade, mas a exibição do vazio incessante que a máquina da cultura ocidental conserva em seu centro.” (AGAMBEN, 2017, p. 298). O inoperoso é fundamental nesse projeto - e também na leitura que faço dos acontecimentos de junho de 2013. Segundo Daniel Nascimento (2014), é na obra O reino e a glória ([2007]2011) que, pela primeira vez, Agamben vai apresentar, numa lucidez conceitual, a noção de inoperosidade. A gênese do conceito se dá em três passos: o primeiro, na tentativa de mostrar o paralelo entre a monarquia divina e a monarquia humana na compreensão do poder político; o segundo, na busca por evidenciar que a inoperosidade já está nos atributos próprios tanto da monarquia humana quanto da monarquia divina; e terceiro, que é necessário pensar em um novo modo de inoperosidade que nos auxilie na abertura de caminhos políticos (NASCIMENTO, 2014, p. 16-17). Neste passo está todo o meu exercício em compreender alguns rastros de junho de 2013, tarefa do próximo tópico.

Pelas discussões elencadas anteriormente, fica evidente a relação entre a monarquia terrena e a monarquia divina. A máquina governamental é uma ressignificação da máquina providencial presente no ser e na práxis da trindade. No fundo, segundo Daniel Nascimento (2014), de acordo com a análise feita por Agamben do tratado pseudoaristotélico Sobre o mundo: “[...] a oposição binária entre essência (ousía) e potência (dynamis) constituem o paradigma da distinção entre ser e agir divinos" (NASCIMENTO, 2014. p. 19). O princípio político-teológico é único, em um modo que gerencia a casa-mundo, sendo ao mesmo tempo - em dois polos - reino e governo, norma transcendente e ordem imanente, mobilidade e imobilidade, soberania e biopolítica.

Junto a isso, vemos que o estado - com referência na tradição cristã e na tradição judaica de algum modo - guarda, através da imagem e necessidade da glória e dos rituais litúrgicos do poder, a memória de um Deus inoperoso. Como pergunta Daniel Nascimento (2014): “O que é o sábado judaico, senão a revelação da inoperosidade como a dimensão mais própria de Deus e dos homens que a ele se dirigem? O que é a vida eterna prometida pelos teólogos do cristianismo, senão a cessão de toda atividade?” (NASCIMENTO, 2014, p. 23). Há no núcleo da monarquia divina e terrena a inoperosidade, uma busca por um fazer não-produtivo. A característica curiosa é que essas mesmas monarquias são guiadas pela lógica produtiva. Quando pensamos no estado moderno, vemos em seu núcleo essa inclusão-exclusão da inoperosidade. É como se no centro do fazer estatal existisse a festa 
encoberta pela burocracia angelical e pela glória. Estamos, portanto, diante de um estado bipolar que possui a própria anarquia dentro de toda ideia de poder.

Desse modo, segundo Colby Dickinson (2017), o projeto de Giorgio Agamben “[...] não é antinomiano no sentido de tentar existir à parte da lei ou do Estado ou da governança” (DICKINSON, 2017, p. 18). Ao indicar que os dualismos que vimos até aqui (como o exemplo do ser e práxis), “[...] são justamente o que legitima relações políticas de dominância e opressão" (DICKINSON, 2017, p. 19), o desejo é romper com essa lógica e com a bindade, para encontrar “[...] o não representável dentro de cada representação, o incognoscível dentro de tudo o pode ser conhecido, o não pensado dentro do próprio pensamento que, ainda assim, fundamenta o pensamento” (DICKINSON, 2017, p. 19).

Em síntese, temos a seguinte formulação feita por Giorgio Agamben (2011):

A oikonomia do poder põe firmemente em seu centro, na forma de festa e glória, aquilo que aparece diante dos seus olhos como a inoperosidade do homem e de Deus, inoperosidade que não se pode olhar. A vida humana é inoperosa e sem objetivo, mas é justamente essa argia e essa ausência de objetivo que tornam possível a operosidade incomparável da espécie humana. O homem se devotou à produção e ao trabalho, porque em sua essência é privado de obra, porque é por excelência um animal sabático. E assim como a máquina da oikonomia teológica só pode funcionar se inserir em seu centro um limiar doxológico em que trindade econômica e trindade imanente transitam litúrgica (ou seja, política) e incessantemente de uma para a outra, assim também o dispositivo governamental funciona porque capturou em seu centro vazio a inoperosidade da essência humana (AGAMBEN, 2011, p. 268).

Com essa construção argumentativa centrada na inoperosidade, como podemos compreender os acontecimentos de junho de 2013? Quais as potências dessa análise?

\section{OS DISPOSITIVOS ACLAMATÓRIOS E AS INOPEROSIDADES DE JUNHO}

Como vimos, o centro da máquina econômica, que a glória tenta encobrir com seus cânticos e cerimoniais, é esse "vazio inoperoso" (AGAMBEN, 2011, p. 180). No entanto, como sinaliza Agamben, hoje os estados ainda possuem seus ritos e cerimônias, mas seguem em sua diminuição e transferências de alguns de seus símbolos para museus ou tesouros (AGAMBEN, 2011, p. 276). 
Para compreender essa questão da glória e o vazio que busca encobrir, Agamben se aproxima das reflexões de Carl Schmitt (2009).11 Primeiro, Agamben resgata a relação entre as aclamações e o direito público, indicando que “[...] não há povo sem publicidade e não há publicidade sem povo" (SCHMITT apud AGAMBEN, 2011, p. 276). Ao dizer isso, Schmitt indica a relação indissociável na política moderna entre aclamação e a democracia, entre aclamação e esfera pública. Sendo mais preciso, “[...] nas democracias contemporâneas, a aclamação sobrevive [...] na esfera da opinião pública, e só partindo do vínculo constitutivo entre povo, aclamação e opinião pública é possível reintegrar em seus direitos o conceito de publicidade.” (AGAMBEN, 2011, p. 277).

Na democracia contemporânea, portanto, a opinião pública é a nova forma de aclamação. O estado permanece necessitando da glória para existir, deslocando-a das grandes cerimônias, ritos e protocolos para a mídia (AGAMBEN, 2011, p. 278). De maneira hegemônica, podemos dizer que a democracia atual se caracteriza como uma democracia liberal. Na leitura de Chantau Mouffe (2003), uma sociedade democrática, na perspectiva do liberalismo, se mostra como uma “[...] sociedade pacificada e harmoniosa, onde as divergências básicas foram superadas e onde se estabeleceu um consenso imposto a partir de uma interpretação única dos valores comuns.” (MOUFFE, 2003, p. 11). Temos aqui uma democracia do consenso, possível somente graças às aclamações atuais: a opinião pública. Aclamação presente em abordagens de C. Schmitt (como "glória imediata e subjetiva do povo") ou nas leituras de Habermas (como "glória midiática e objetiva da comunicação social”) (AGAMBEN, 2011, p. 280). Temos, assim, esquemas aparentemente opostos - o agir comunicativo, do último e a ideia de que "Só o povo efetivamente reunido e presente é povo e produz a publicidade." (SCHMITT apud AGAMBEN, 2011, p. 276), do primeiro. Nos dois casos, diz Agamben, temos nada mais que "[..] duas faces do mesmo dispositivo glorioso em suas duas formas: a glória imediata e subjetiva do povo aclamante e a glória midiática e objetiva da comunicação social” (AGAMBEN, 2011, p. 280). Em síntese, a opinião pública acontece nos entrelaçamentos e separações entre o "[...] povo-nação e o povo-comunicação [...]” (AGAMBEN, 2011, p. 280-282), uma opinião que é glória e doxologia.

\footnotetext{
${ }^{11}$ A importante discussão realizada por Giorgio Agamben, em relação a esse autor, tem a referência na obra Teologia política (SCHMITT, 2009). Para o aprofundamento desse debate, há uma investigação que realizo no terceiro capítulo da minha tese de doutorado: “A vida nua: exceção e soberania" (SOUZA, 2019). Há nesse estudo, especialmente, análises sobre C. Schmitt e W. Benjamin a partir do pedido de prisão emitido pelo juiz Flávio Itabaiana de Oliveira Nicolau, no Rio de Janeiro, para os jovens Elisa de Quadros Pinto Sanzi, Igor Mendes da Silva e Kalayne Moraes da Silva Pinheiro, que foram atuantes nos acontecimentos de junho de 2013 e nas manifestações na Copa do Mundo de 2014.
} 
Fabián Ludueña (2017) aprofunda essa interpretação que faço de Agamben. Para ele, “[...] a liturgia se constituirá exatamente em um instrumento privilegiado para introduzir uma dinâmica politizadora, no seio de uma multidão, para conferir-lhe caráter político.” (LUDUEÑA, 2017, p. 62). A glória se relaciona com o governo de consenso. No entanto, é preciso complexar essa vinculação entre democracia gloriosa e os meios de comunicação, compreender os novos e velhos ritos políticos e os seus significados “[...] antropotécnicos.” (LUDUEÑA, 2017, p. 63). As aclamações nos atuais sistemas democráticos são uma combinação que vão desde as "[...]formas de reconhecimento público tradicionais com multidões presentes até a desmaterialização completa da presença do organismo público e sua translação in toto às esferas dos mundos digitais" (LUDUEÑA, 2017, p. 62). Estamos diante de ecossistemas cibernéticos e de suas combinações com modos de aclamações mais próximas de uma política tradicional. São novas formas, bricoladas, de exercício de liturgia e constituição de consensos. Em junho de 2013 encontramos - de maneira significativa - o uso desses ecossistemas cibernéticos. Mas não podemos compreender as redes isoladamente. Elas são um “[...] agenciamento: humano/máquina, rede 'concretas'/rede 'virtual'; não a ferramenta em si, como se ela fosse dotada de poderes mágicos e autônomos, mas dos significados e subversões promovidos pelos ativistas" (MORAES, 2014, p. 19). Na mesma linha segue Rodrigo Bolton (2017) que, ao estudar as primaveras árabes, indica essas revoltas como uma experiência de “[...] libertação da imaginação política de entraves espetaculares. Não guarda relação com a presença ou não das famosas e fetichizadas 'redes sociais'.” (BOLTON, 2017, p. 27). O ponto latente é que essas mobilizações ineficientes foram uma "[...] aposta de uma espécie de potência destituinte que foi capaz de dar novo uso para as imagens que tinham sido capturadas pelos respectivos 'marcos de guerra' do espetáculo midiático” (BOLTON, 2017, p. 27). Junho também foi desse modo.

As grafias abaixo nos ajudam a compreender a frase que é a epígrafe desse artigo, pois os acontecimentos de junho deixam o rei nu. Para esse exercício interpretativo, resgato um cartaz segurado por uma mulher negra na cidade de Timóteo (MG). Em seu rosto, o símbolo das caras pintadas de 1992, conforme figura 1:12

\footnotetext{
12 As fotografias utilizadas nesse artigo foram retiradas do site Grafias de junho, organizado por Roberto Andrés (2013), como parte de seu projeto de pesquisa - doutorado em História das Cidades, e apoio das bolsistas Ana Caroline Azevedo, Mirela Matos e Bárbara Contarini. Projeto colaborativo para reconstituição da memória histórica, no Grupo de pesquisa Cosmópolis - UFMG, em colaboração com o Laboratório para Outros Urbanismos da Faculdade de Arquitetura e Urbanismo da USP.
} 


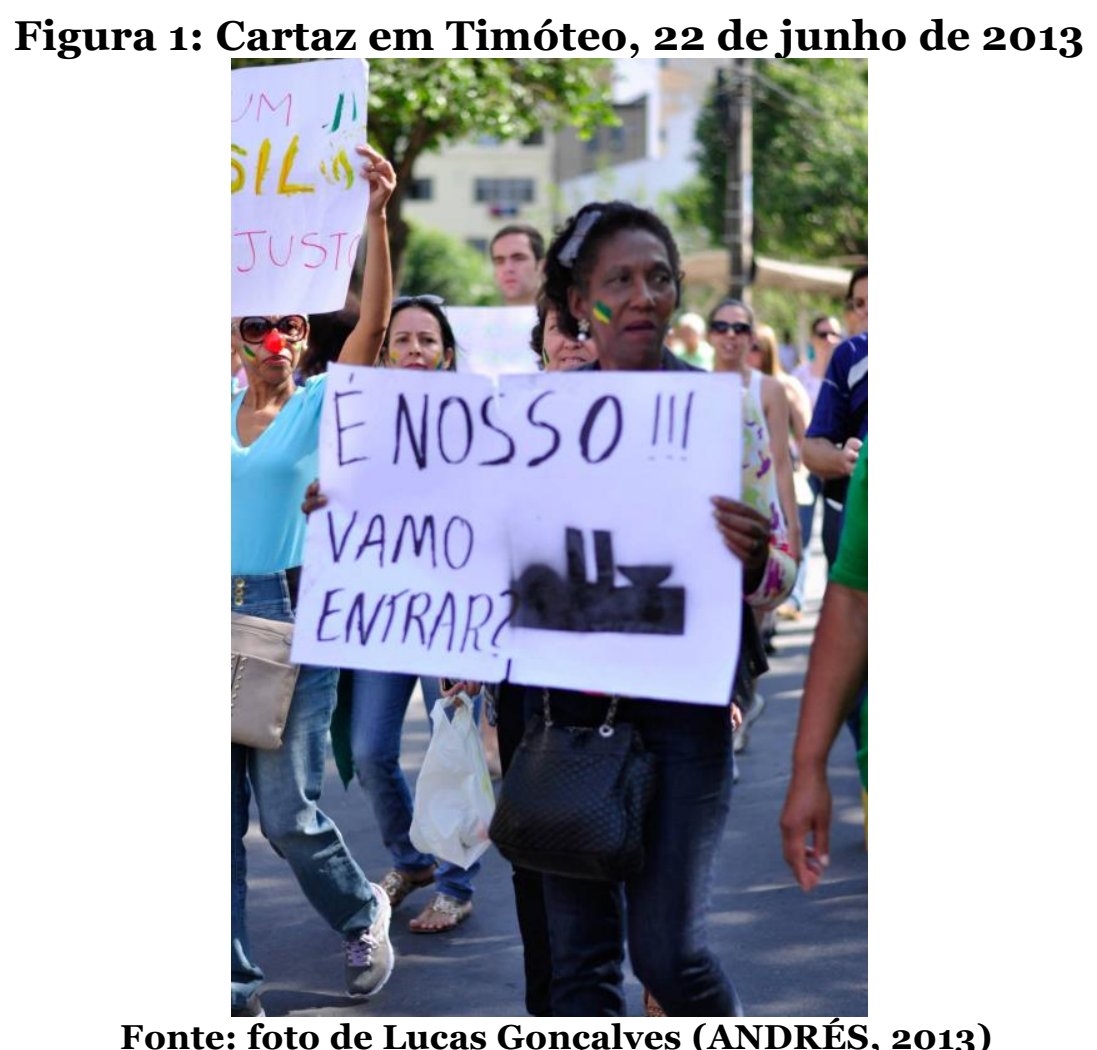

Os dispositivos aclamatórios do estado são centrais na democracia e suas representações, em que se tenta, segundo Rodrigo Bolton (2017), "[...] governar a totalidade micro e macrofísica da vida social nas sociedades neoliberais, produzindo o 'consenso' como um dispositivo de governo.” (BOLTON, 2017, p. 27). Há, aqui, uma separação. Quem decide os rumos da política? Desde a teologia trinitária estudada por Giorgio Agamben, encontramos uma máquina governamental que parece englobar tudo. O papel esperado, na dinâmica da civilidade, é a obediência e atuação política dentro dos espaços estabelecidos e construídos de participação social. Algo também visto nos gestos políticos feitos pelo então prefeito Fernando Haddad (PT) com o MPL. O símbolo do cartaz - o poder legislativo - é o espaço da distância. Quando estava no Conselho Nacional de Juventude, ${ }^{13}$ me lembro das dificuldades e protocolos para se chegar em cada um desses espaços. Roupa adequada. Terno. Gravata. Cuidado com o barulho. Trajetos sem muita aglomeração. Corpos revistados. Mochilas sempre revistadas. Tudo feito para não entrar, para não habitar o espaço do povo.

Também me lembro da primeira vez em que fui ao Palácio do Planalto. Era uma reunião com a presidenta Dilma Rousseff (PT), em 10 de abril de 2014. O contexto: o

${ }^{13}$ Estive no Conselho Nacional de Juventude entre 2011-2017, nos dois últimos anos como presidente. 
encontro da presidenta com organizações ligadas à Jornada de Lutas da Juventude. ${ }^{4}$ Esse momento seguia a linha das reuniões realizadas em 2013. Uma com a própria Jornada de Lutas, em 04 de abril de 2013; e outra com o Movimento Passe Livre - MPL, em 24 de junho de 2013. Não quero dar ênfase sobre as pautas discutidas no encontro.15 Quero resgatar a glória da democracia que ali vivenciei. As pessoas que representavam as entidades chegaram em Brasília, um dia antes. Eu lá estava, pela Rede Ecumênica da Juventude (REJU). A chegada antes do dia marcado era para se ajustarem as pautas e as pessoas que falariam no encontro com a presidenta. Majoritariamente, tínhamos ali organizações mais tradicionais diante de junho de 2013. Quem fala perante a autoridade? O que diz? Como diz? Há fissuras importantes nas dinâmicas e protocolos estatais. Mas no centro: estávamos reunidos para ordenar a atuação no dia seguinte - mediados pela Secretaria Nacional de Juventude, um braço da Secretaria-Geral da Presidência. Acordos estabelecidos, nomes escolhidos, pautas delimitadas.

Chega o dia.

Na noite, só pensava que encontraria a presidenta da república e que precisava informalmente - dizer algumas palavras sobre a importância do estado laico. Informalmente, porque não estava entre os nomes que falariam pela jornada de lutas. Seguimos o protocolo da Presidência. Havia um número estabelecido e permitido para se pronunciar. Seguimos alguns critérios. Ao chegar no local, seguranças, credenciamentos, novos protocolos. Caminhamos pelos espaços daquele prédio. Algumas fotos. Estávamos ali, no Palácio. O próprio nome já carrega a sua glória. Todos em uma sala de reunião sem celulares. A mesa já trazia os lugares com os nomes de cada pessoa. Tudo já estava definido. Sentaria próximo à Dilma. Antes, algumas conversas entre os representantes da juventude - a reunião tinha esse caráter. Depois: silêncio. Anunciaram: a presidenta está vindo. Todos nós, quietos, à sua espera. Um certo calafrio. Talvez até medo diante dessa liturgia estatal. Ela - sabemos bem - produz efeitos de subjetivação. Uma captura na identidade de cidadão? Abre-se uma porta lateral. De lá saem alguns representantes da Secretaria-Geral. Por último, como em uma encenação com um fim esperado e aclamado, aparece a presidenta. Ela abraça e beija cada um. Quer saber o nosso nome e a nossa

\footnotetext{
${ }^{14}$ A Jornada Nacional de Lutas da Juventude é uma mobilização nacional que integra "[...] entidades estudantis, as juventudes do movimento social, dos trabalhadores (as), da cidade, do campo, as feministas, os negros e negras, as juventudes partidárias, religiosas, lgbt, dos coletivos de cultura e das periferias" (SALVADOR, 2014).

15 Para isso, confira o texto de Aurea Carolina (2020).
} 
entidade. Algo que manda o protocolo. Só consegui dizer meu nome. Lembro que olhei bem em seu rosto. A reunião acontece sem muitas surpresas - apenas um ou outro comentário de um participante que não estava bem ensaiado no acordo do dia anterior. Nada tão fora do jogo. No fim, algumas fotos e conversas informais. Parece que se desmontou o protocolo. Quando ela voltava para aquela mesma porta por onde entrou, eu e uma amiga pedimos para tirarmos uma foto. Ela sorri e aceita. Na mesma hora, já aparece outra pessoa pedindo a mesma coisa: - posso tirar uma foto?

Eu me encontrei com Dilma outras vezes. Uma na campanha eleitoral de 2014, no Alvorada (07 de setembro); e outra na $3^{\text {a }}$ Conferência Nacional de Juventude, no Estádio Mané Garrincha (o9 de dezembro de 2015). Nessa última, com mais espaço de diálogo e interação. Mas o protocolo e as regras nunca abandonaram nenhum desses momentos. A democracia gloriosa não se organiza também na manutenção desses espaços e distâncias, nessas lógicas de aclamação? A máquina governamental - para esconder o seu vazio, seu nada - produz sinais imaginários de poder: “[...] elogios, adoração, despesas enormes em ornamentos, formas de culto, canções ou hinos podem ser parte de uma complexa trama gloriosa" (BOLTON, 2017, p. 19).

Aqui está a potência da grafia que escolhi. Junho coloca em questão o vazio. No fundo, encontramos um nada no dito poder. Se o poder "[...] não é uma substância, mas uma relação e, como tal, não pode funcionar senão como formas muito precisas de glorificação. Se a máquina exibe o trono vazio que a glorificação tenta ocultar, ela é desativada" (BOLTON, 2017, p. 19). É nosso, vamo entrar? nos coloca diante do vazio do símbolo. Quem nos governa?

Por isso, concordo com Paulo Arantes (2014) quando ele afirma que junho foi sobre "[...] como somos governados, como nos governamos e como agora não queremos mais saber disso" (ARANTES, 2014, p. 453).

Isso é tão teológico! Por que continuar em lógicas de construção de consenso e na adoração a qualquer imaginário de deus - como o estado, o capital ou a trindade? $\mathrm{Na}$ figura 2, a grafia abaixo - do Rio de Janeiro - é emblemática em relação a isso: 


\section{Figura 2: Pichação no Rio de Janeiro, 17 de junho de 2013}

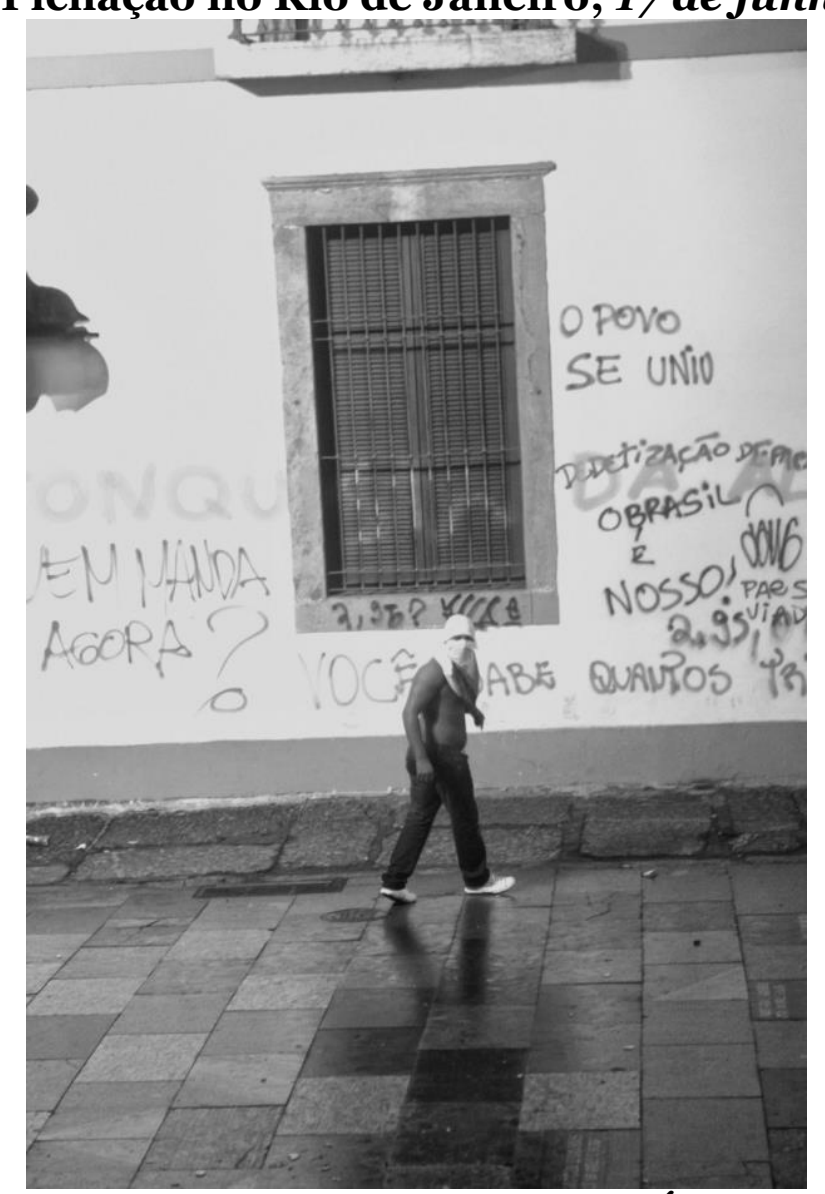

Fonte: foto de Marcelo Valle (ANDRÉS, 2013)

Quem manda agora?. O povo se uniu. O Brasil é nosso. Ruas e paredes ocupadas. Corpos sem nome. Rostos tapados testemunham a sua dessubjetivação diante de uma máquina governamental - e letal - que a tudo quer capturar? Se, conforme Rodrigo Bolton (2017), na praça Tahrir "[...] a liturgia do regime experimentou sua implosão e o povo egípcio voltou a dar uso às suas imagens, longe de suas formas aclamatórias" (BOLTON, 2017, p. 28); em junho, encontramos a rua como o espaço da reinvenção e do desbloqueio de imaginações e novos usos dos símbolos e sinais. Junho, se quisermos seguir uma gramática de Agamben, pode liberar o impensado (BOLTON, 2017). Queima-se a catraca, o posto da polícia. Evidencia-se a inoperosidade, a anarquia de todo poder. Não desde a eficiência político-estratégica. Não há programa de cima para baixo, com um futuro organizado e já estruturado. Daniel Nascimento (2014) nos ajuda a pensar sobre isso: a "[...] inoperosidade não é algo inerte [...]", diz ele. Por isso, "[...] o que nela é desativado não é a potência em si, que permanece, mas a finalidade e a modalidade do exercício da potência. O que nela é desorientado é o uso mais óbvio. E um novo uso possível" (NASCIMENTO, 2014, p. 25). O óbvio e esperado coloca junho, por exemplo, 
diante dos caminhos políticos institucionais de uma democracia participativa e representativa que entra em colapso. Fazer dos corpos na rua sujeitos de direito na administração dos bens públicos e em uma participação administrativa? Diante dos lugares construídos como espaços para escuta do povo pelo estado, uma grafia de junho na figura 3:

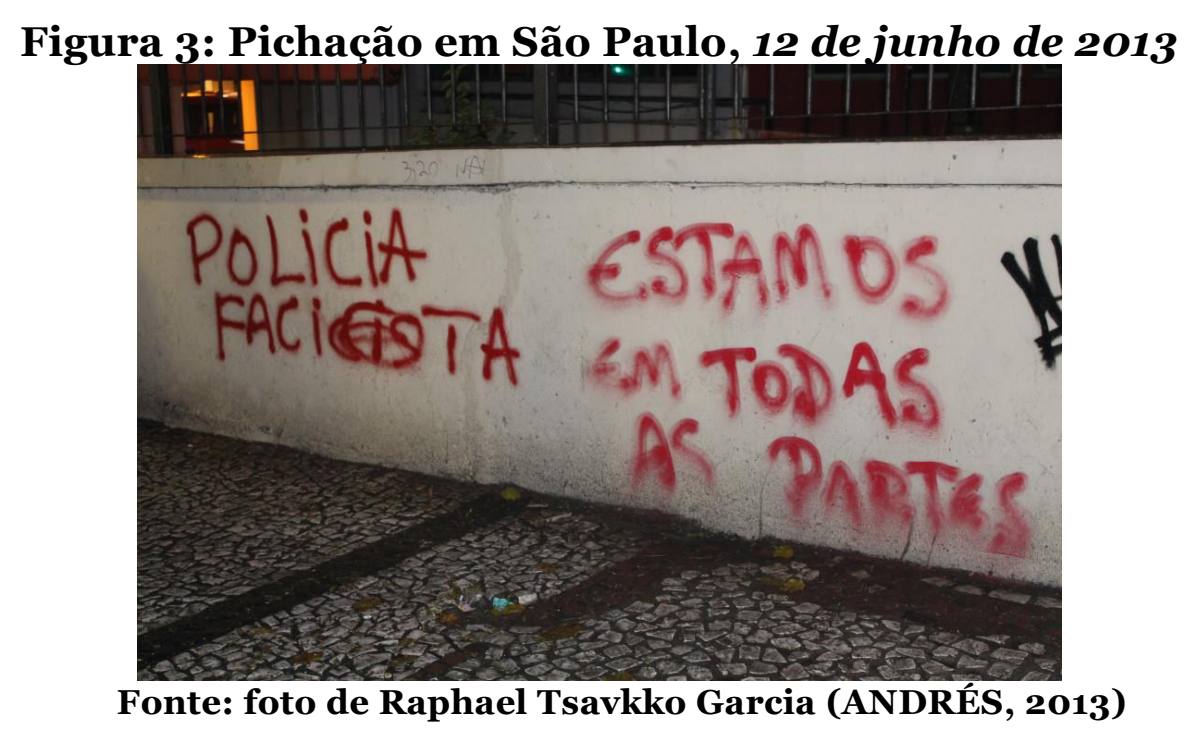

Estamos em todas as partes. O corpo vaza. A potência é intensidade que pode nos colocar para além da bindade governamental que a tudo deseja controlar. Inclusive a potência como possibilidade de criar o impensado. A glória de uma divindade é desvelada. Toca-se no sagrado. As reações às vezes são sutis. Daniel Nascimento (2014) traz uma boa lembrança de junho. O principal resultado na semana do dia 17, com marcas fortes de insatisfação com a representatividade do sistema político em todas as ruas, foi "[...] uma maratona de trabalho sem precedentes no Congresso Nacional” (NASCIMENTO, 2014, p. 104). Como ele afirma de maneira correta: “[...] as instituições do nosso tempo procuram resolver a crise de legitimidade com a acentuação da legalidade" (NASCIMENTO, 2014, p. 104). O exemplo sobre junho é a própria aprovação do Estatuto da Juventude pelo Congresso e a sanção feita pela presidenta Dilma (05 de agosto de 2013). Muitos integrantes do CONJUVE defendiam que esse marco legal, engavetado por quase dez anos, só foi possível devido às ruas de junho. Quase como se no pedido dos corpos ingovernáveis viesse junto a urgência de mais legalidade como símbolo de mais direitos. Não duvido que junho tenha movido essas instâncias. O problema é a interpretação feita pelos poderes executivo e legislativo e por parte da sociedade civil, como se o estado tivesse compreendido junho e 
tivesse dado uma resposta à altura, aos clamores da rua. ${ }^{16}$ No fundo, esses poderes não compreenderam que, para além do princípio da legalidade, vivemos uma “[...] crise de legitimidade do poder, crise de fundação, crise que não pode ser resolvida apenas no campo do direito" (NASCIMENTO, 2014, p. 104).

\section{CONSIDERAÇÕES FINAIS}

Encerro esse artigo, que vincula teologia \& política, com um elemento importante: o desejo. Junho colocou em questão a vida que desejamos. Sobre isso, me interesso pelas reflexões de Sueli Rolnik. Em um texto sobre $A$ hora da micropolítica (2016), ela defende que a nova estratégia política do capitalismo (financeirizado, neoliberal e globalizado) não é mais a tomada do poder por meio da força militar, como aconteceu nas décadas de 1960, 70 e 80 , mas sim a tomada da "[...] força do desejo - ou seja a força vital que move a existência individual e coletiva" (ROLNIK, 2016, p. 3). Quando percebemos as dinâmicas e as relações de poder em junho de 2013, nos encontramos diante de estratégias micropolíticas relacionadas com práticas macropolíticas (como a atuação do estadocapital). Tomar o desejo é tomar a possibilidade de imaginar e sonhar iniciativas de resistência para além dos espaços e projetos estabelecidos - com toda a glória. Como desbloquear o desejo capturado pelo estado-capital? Como, diante do desenvolvimento de um fascismo generalizado - como dizia G. Deleuze -, pode-se “[...] montar uma máquina revolucionária capaz de se fazer cargo do desejo e dos fenômenos de desejo"? (DELEUZE, 2013, p. 29).

Se vincularmos essas leituras ao pensamento de G. Agamben, podemos resgatar o conceito de forma-de-vida, uma vida que jamais é possível isolar uma vida nua. Uma vida não capturada pela exceção. Assim, a vida humana - em sua singularidade - não é meramente um fato, "[...] mas sempre e primeiramente possibilidade de vida, sempre e primeiramente potência” (AGAMBEN, 2015, p. 14). Se procurei mostrar como o estado moderno e sua máquina governamental só são possíveis em sua relação e assinatura com uma máquina providencial que marca a trindade/bindade, também evidenciei que no

\footnotetext{
${ }_{16}$ Euzébio de Sousa apresenta um estudo sobre essa vinculação no texto Relação complementar entre democracia participativa e representativa: manifestações de Junho de 2013 e a aprovação de Estatuto da Juventude (2014). Em um questionário, diante da pergunta: "A aprovação e sanção do Estatuto da Juventude foi uma resposta do governo federal às reivindicações das manifestações de Junho de 2013?”, 75\% dos conselheiros entrevistados indicam que sim, 9\% afirmam que não, $8 \%$ dizem que indiretamente, $4 \%$ falam que talvez e $4 \%$ indicam que essa resposta acontece parcialmente. Diante de uma segunda questão: "A aprovação e sanção do Estatuto da Juventude contemplam algumas das reivindicações das manifestações de Junho de 2013?”, os conselheiros em sua grande maioria (92\%) dizem que sim (SOUSA, 2014, p. 51-52).
} 
centro desse jogo há um vazio, um hiato que precisa ser escondido pelas dinâmicas de glorificação e aclamação de nossas democracias. A potência talvez esteja aqui: como escancarar o vazio do estado como sua inoperosidade encoberta pela glória? Como aprofundar os rastros destituintes dos corpos que desejam outros modos de vida desde alianças e de reinvenções de um agir político que não se deixa enclausurar nos acordos da política transformada em técnica (na economia ou no direito)? As indicações que encontrei em junho podem nos favorecer em possibilidades imaginativas para se perceber outros usos da política. Mas sem programas a seguir, sem cartilhas a aplicar.

\section{REFERÊNCIAS}

AGAMBEN, G. Meios sem fim: notas sobre a política. Belo Horizonte: Autêntica editora, [1996] 2015.

AGAMBEN, G. O aberto: o homem e o animal. Rio de Janeiro: Civilização Brasileira, [2002] 2013.

AGAMBEN, G. O reino e a glóriaa: uma genealogia teológica da economia e do governo. São Paulo: Boitempo, [2007] 2011.

AGAMBEN, G. O uso dos corpos: Homo Sacer, IV, 2. São Paulo: Boitempo, [2014] 2017. ANDRÉS, Roberto. Grafias de junho. Projeto colaborativo para reconstituição da memória histórica. 2013. Disponível em: https://www.grafiasdejunho.org/principal. Acesso em: 20 maio 2020.

ARANTES, Paulo. O novo tempo do mundo. São Paulo: Boitempo, 2014.

ALCKMIN, G. Entrevista cedida em Coletiva de Imprensa. In: BALZA, Guilherme. Ao anunciar que tarifa volta a R\$ 3, Alckmin e Haddad falam em "sacrifício" e corte de investimentos. 2013. UOL, São Paulo, 19 jun. 2013. Disponível em: http://twixar.me/R4CK. Acesso em: 29 maio 2020.

BOLTON, Rodrigo K. O impensado como potência e a desativação das máquinas de poder. Cadernos IHU Ideias. São Leopoldo, ano 15, v. 15, n. 258, 2017.

CAROLINA, Aurea. Juventude negra pauta governo sociedade. Secretaria Nacional de Juventude - SNJ. Disponível em: http://twixar.me/cyxK. Acesso em 29 maio 2020.

CARVALHO, Laura. Valsa Brasileira: do boom ao caos econômico. São Paulo: Todavia, 2018.

CASTRO, Edgardo. Introdução a Giorgio Agamben: uma arqueologia da potência. Belo Horizonte: Autêntica, 2013.

CHIGNOLA, Sandro. Tecnicização da decisão política é uma das assinaturas da contemporaneidade. Em: IHU-UNISINOS. São Leopoldo, ano XVII, n. 505, p. 31-36, maio, 2017.

COMITÊ INVISÍVEL. Aos nossos amigos: crise e insurreição. São Paulo: N-1 Edições, 
2016.

DELEUZE, Gilles. Conversações. São Paulo: Editora 34, 2013.

DICKINSON, Colby. A glória como arcano central do poder e os vínculos entre oikonomia, governo e gestão. Cadernos Teologia Pública. São Leopoldo, ano XIV, v. 14, n. 127, 2017.

FOUCAULT, Michel. História da sexualidade - a vontade de saber. v. 1. São Paulo: Editora Paz \& Terra, 2017.

FRASER, Kyle A. The Contested Boundaries of Magic and Religion in the Late Pagan Monotheism. In: Magic, Ritual, and Witchcraft, v. 4, n. 2, 2009, p. 131-151. Disponível em: https://muse.jhu.edu/article/364065. Acesso em: 29 maio 2020.

GIACOIA JUNIOR, Oswaldo. Por uma ética da vergonha e do resto. São Paulo: N-1 Edições, 2018.

HADDAD, F. Entrevista cedida em Coletiva de Imprensa. In: BALZA, Guilherme. Ao anunciar que tarifa volta a R\$ 3, Alckmin e Haddad falam em 'sacrifício' e corte de investimentos. 2013. UOL, São Paulo, 19 jun. 2013. Disponível em: http://twixar.me/R4CK. Acesso em: 29 maio 2020.

HADDAD, Fernando. Vivi na pele o que aprendi nos livros. In: Revista Piauí. São Paulo, n. 129, jun. 2017.

JUDENSNAIDER, Elena; LIMA, Luciana; POMAR, Marcelo \& ORTELLADO, Pablo. Vinte centavos: a luta contra o aumento. São Paulo: Veneta, 2013.

LEXICON. Dicionário teológico enciclopédico. São Paulo: Edições Loyola, 2003.

LUDUEÑA, Fabián. Nenhum sistema político funciona sem o elemento glorioso. In: IHUUNISINOS. São Leopoldo, ano XVII, n. 505, p. 61-65, maio 2017.

MORAES, Alana et al (org.). Junho: potência das ruas e das redes. São Paulo: Friedrich Ebert Stiftung (FES) Brasil, 2014.

MOUFFE, Chantal. Democracia, cidadania e a questão do pluralismo. Política \& Sociedade. Florianópolis, v. 3, n. 03, p. 11-26, out. 2003.

NASCIMENTO, Daniel Arruda. Umbrais de Giorgio Agamben: para onde nos conduz o homo sacer? São Paulo: Editora LiberArs, 2014.

RIEGER, Joerg. Cristo e Império: de Paulo aos tempos pós-coloniais. São Paulo: Paulus, 2009.

ROLNIK, Sueli. A hora da micropolítica. Coleção Pandemia. São Paulo: N-1 Edições, 2016.

ROUSSEFF, Dilma. Pronunciamento da presidenta Dilma Rousseff. Editado por Fábio Massalli. EBC. 27 jun. 2013. Disponível em: http://twixar.me/X4CK. Acesso em: 29 maio 2020.

RUIZ, Castor Bartolomé. Giorgio Agamben, liturgia (e) política: por que o poder necessita da glória? Revista Brasileira de Estudos Políticos. Belo Horizonte, n. 108, p. 185-213, jan./jun. 2014. 
SALVADOR, Yuri. Jornada de lutas 2014. A força da juventude nas ruas! UNIÃO

NACIONAL DOS ESTUDANTES, 15 abr. 2014. Disponível em:

https://une.org.br/2014/o4/jornada-de-lutas-2014-a-forca-da-juventude-nas-ruas/. Acesso em: 30 maio 2020.

SCHMITT, Carl. Teología Política. Madri: Editorial Trotta, 2009.

SEREJO, Lincoln Sales. Angelologia e burocracia na obra O reino e a glória de Giorgio Agamben. Rev. Interd. em Cult. e Soc. (RICS), São Luís, v. 4, n. especial - dossiê temático. p. 213-224. 2018.

SOUSA, Euzébio Jorge Silveira de. Relação complementar entre democracia participativa e representativa: manifestações de junho de 2013 e a aprovação do estatuto da juventude. Programa de formação de conselheiros nacionais - Democracia participativa, república e movimentos sociais. Belo Horizonte: UFMG, 2014.

SOUZA, Daniel Santos. A revolta da ineficiência: os acontecimentos de junho de 2013 no Brasil e suas destituições político-teológicas. 2019. 349 p. Tese (Doutorado em Ciências da Religião) - Universidade Metodista de São Paulo, São Bernardo do Campo.

Recebido em: 24 out. 2019 Aprovado em: 30 maio 2019 